\section{e0274 THE BLOOD PRESSURE CONTROL RATE OF CHINESE OUTPATIENTS WITH CORONARY HEART DISEASE: A CROSS-SECTIONAL STUDY}

doi:10.1136/hrt.2010.208967.274

${ }^{1}$ Zhu Yun, ${ }^{2}$ Li Xiankai, ${ }^{3}$ Oin Liqiang, ${ }^{1}$ Wu Lezhou, ${ }^{1}$ Li Jun, 'Li Jue. ${ }^{1}$ Tongji University; ${ }^{2}$ Shanghai Tenth Peoples Hospital; ${ }^{3}$ Soochow University

Objectives To investigate the current status of blood pressure (BP) treatment-goal in outpatients with coronary heart disease (CHD) in China and to identify the independent risk factors of BP treatment goal achievement in these outpatients.

Methods In this cross-sectional survey, participants with CHD aged $\geq 35$ years were recruited from 66 hospitals from June 2006 to January 2007 in Beijing, Shanghai, Tianjin, Guangdong, Zhejiang and Xinjiang in China.

Results $68.6 \%$ of the subjects had hypertension (female $76.0 \%$ vs male $64.5 \%, \mathrm{p}<0.001)$. The goal of $\mathrm{BP}$ achievement was $\mathrm{SBP}<130$ $\mathrm{mm} \mathrm{Hg}$ and $\mathrm{DBP}<80 \mathrm{~mm} \mathrm{Hg}$ for CHD outpatients in this study. The success rate for achieving the $\mathrm{BP}$ target in $\mathrm{CHD}$ outpatients was $26.4 \%$ (female $23.1 \%$ vs male $28.3 \%, p<0.001$ ). The success rate for achieving the BP target in CHD outpatients was $18.1 \%$. The independent risk factors of achieving the $\mathrm{BP}$ target for $\mathrm{CHD}$ outpatients with hypertension were BMI $\geq 23 \mathrm{~kg} / \mathrm{m}^{2}$, minority nationalities and use of statins. The OR of these risk factors were 1.423 (95\% CI 1.171 to 1.729$), 0.438$ (95\% CI 0.279 to 0.686$)$ and 0.768 (95\% CI 0.593 to 0.995$)$, respectively. The incidence of acute myocardial infarction, percutaneous coronary intervention and coronary artery lesions were significantly higher in CHD outpatients with $\mathrm{SBP}<110 \mathrm{~mm} \mathrm{Hg}$ and/or $\mathrm{DBP}<60 \mathrm{~mm} \mathrm{Hg}$ than those in CHD outpatients with SBP $\geq 110 \mathrm{~mm} \mathrm{Hg}$ and DBP $\geq 60 \mathrm{~mm} \mathrm{Hg}$ $(\mathrm{p}<0.001)$.

Conclusion This survey demonstrated the success rate for achieving the BP target was low in Chinese CHD outpatients, especially in CHD outpatients with hypertension. BMI $\geq 23 \mathrm{~kg} /$ $\mathrm{m}^{2}$, minority nationalities and use of statins were the independent risks of achieving the $\mathrm{BP}$ target for $\mathrm{CHD}$ outpatients with hypertension.

\section{e0275 BETTER CRITERION SCREENING FOR LEFT VENTRICULAR HYPERTROPHY BY ELECTROCARDIAGRAM WITH DIFFERENT PURPOSES}

doi:10.1136/hrt.2010.208967.275

${ }^{1}$ Song Ai, ${ }^{2} \mathrm{Li}$ Tianchang, 'Wang Ningli, 'Liang Yuanbo, ${ }^{1}$ Peng Yi. ' Beijing Tongren Hospital; ${ }^{2}$ General Navy Hospital

Background According to the Recommendations for the Standardisation and Interpretation of the ECG of AHA/ACCF/HRS declared in 2009, there are more than 30 criteria for diagnosing left ventricular hypertrophy (LVH). The sensitivity of the various criteria is generally quite low. However, the specificity of ECG in LVH could be $85-90 \%$, acting as a strong predictor for cardiovascular events.

Purpose To investigate the proper criteria in epidemiological screening with different purpose.

Method 5209 qualified ECG out of 6830 people were selected from cross-sectional Handan Eye Study. 2 criteria were chosen: (1) Sokolow-Lyon index-sum of SV1+RV5 or V6 $\geq 35 \mathrm{~mm}$; (2) Cornell voltage duration product-men: $(\mathrm{SV} 3+\mathrm{RaVL}) \times \mathrm{QRS}$ duration $\geq 2440$ ms; women: $(\mathrm{SV} 3+(\mathrm{RaVL}+8 \mathrm{mV})) \times$ QRS duration $\geq 2440$ $\mathrm{ms}$. The ECG-LVH group contains 829 individuals $(12.18 \%$ of the cohort), including 607 by Sokolow-Lyon index and 278 by Cornell voltage duration product.
Result After estimated data, we found there is no statistical differences between ECG-LVH population and normal population. While evaluated these data in the group that have Retionopathy without diabetes, the Sokolow-Lyon index and Cornell voltage duration product are statistically different with normal population ( $p=0.023, p=0.014$, respectively). We use the simple MMSE to evaluated the mental status of the population, and found that when the score above 15 , there is no statistically different between the positive and negative people in Sokolow-Lyon index $(p=0.135)$; however, while evaluated Cornell voltage duration product, there is statistically difference $(p=0.001)$. When evaluated the data associated with atherosclerotic factors, we find no differences in Cornell Voltage-Duration Product; as for the Sokolow-Lyon index, the differences are shown in systolic blood pressure, total cholesterols and uric acid $(p=0.03,0.04,0.04$, respectively).

Conclusion Different criterion should be chosen for different purposes. For atherosclerotic screening or epidemiological survey of cardiovascular diseases, the Sokolow-Lyon Index might be better. If we use the criterion for epidemiological ophthalmology such as our Handan Eye study, both Sokolow-Lyon Index and Cornell voltage duration Product could be used. As for the evaluation of mental status and its relationship with the LVH risk factors, we might choose Cornell voltage duration product.

\section{e0276 LONG-TERM FOLLOW-UP OF THE ELDERLY PATIENTS WITH ATHEROSCLEROTIC RENAL ARTERY STENOSIS TREATED BY PERCUTANEOUS TRANSLUMINAL ANGIOPLASTY WITH STENT IMPLANTATION (PTRAS)}

doi:10.1136/hrt.2010.208967.276

Jiahui Zhao, Qingli Cheng, Xiaoying Zhang. Chinese Pla (people's Liberation Army) General Hospital

Objectives To evaluate if PTRAS in the elderly patients with atherosclerotic renal artery stenosis (ARAS) can have long-term effect on hypertension and renal function.

Methods To retrospectively collect the data of the elderly patients cases with ARAS diagnosed by angiography (stenosis $\geq 70 \%$ ). 65 PTRAS were performed. The average age of the group was $76.1 \pm 5(67-88)$ years. The median follow-up was 30.9 months.

Results There were significant decrease in BP (before, 153.8 \pm 23.5 / $78.6 \pm 11.3 \mathrm{~mm} \mathrm{Hg}$ vs after, 131.8 $\pm 13.9 / 68.9 \pm 8.3 \mathrm{~mm} \mathrm{Hg}$; $<0.01)$ at the third day after PTRAS and the decrease of BP remained till 36 months after PTRAS. The mean number of antihypertensive drugs also decreased from $2.29 \pm 1.06$ to $2.08 \pm 1.04$. The incidence of Contrast-induced nephropathy was $9.2 \%$. Logistic regression analysis showed that factors concerning complicated with diabetes mellitus, GFR $\leq 30 \mathrm{ml} / \mathrm{min} / 1.73 \mathrm{~m}^{2}$, systolic pressure $\geq 180 \mathrm{~mm}$ $\mathrm{Hg}$ and hydration therapy showed significant relationship with the incidence of CIN ( $p=0.0072 ; O R=13.51 ; p=0.0002 ; O R=519.27$; $p=0.0134 ; \quad O R=13.16$ and $p=0.0266 ; \quad O R=0.10 ;$ respectively). Renal function improved in $9.1 \%-15.8 \%$ of patients and was stabilised in $67.3 \%-55.3 \%$ of them and deteriorated in $23.4 \%-$ $28.9 \%$ of patients in $12-36$ months after PTRAS. Logistic regression analysis showed that patients with diabetes mellitus have more dangerous in the deterioration of renal function at 12 months after PTRAS ( $p=0.0277 ; O R=6.32)$. The restenosis rate was $13.8 \%$

Conclusion PTRAS could significantly decrease blood pressure level in the elderly patients with ARAS in 36 months after operation. The improvement of renal function in the elderly patients with ARAS after PTRAS is limit. 